\title{
SARS-COV2 Seroprevalence in a Cohort of Perinatally HIV Infected Children and Young Adults From May to December 2020 in Italy
}

Chiara Casamento Tumeo ( $\sim$ chiara.casamento@opbg.net)

Bambino Gesu Pediatric Hospital: Ospedale Pediatrico Bambino Gesu https://orcid.org/0000-00022035-6886

\section{Nicola Cotugno}

Ospedale Pediatrico Bambino Gesu

\section{Luana Coltella}

Bambino Gesu Pediatric Hospital: Ospedale Pediatrico Bambino Gesu

\section{Stefania Ranno}

Bambino Gesu Pediatric Hospital: Ospedale Pediatrico Bambino Gesu

\section{Livia Piccioni}

Bambino Gesu Pediatric Hospital: Ospedale Pediatrico Bambino Gesu

\section{Giulia Linardos}

Bambino Gesu Pediatric Hospital: Ospedale Pediatrico Bambino Gesu

\section{Luna Colagrossi}

Bambino Gesu Pediatric Hospital: Ospedale Pediatrico Bambino Gesu

\section{Carlo Concato}

Bambino Gesu Pediatric Hospital: Ospedale Pediatrico Bambino Gesu

\section{Carlo Federico Perno}

Bambino Gesu Pediatric Hospital: Ospedale Pediatrico Bambino Gesu

\section{Stefania Bernardi}

Bambino Gesu Pediatric Hospital: Ospedale Pediatrico Bambino Gesu

\section{Research Article}

Keywords: HIV, SARS-CoV2, serology, HAART

Posted Date: November 16th, 2021

DOI: https://doi.org/10.21203/rs.3.rs-1061389/v1

License: (c) (1) This work is licensed under a Creative Commons Attribution 4.0 International License. Read Full License 


\section{Abstract}

SARS-CoV2 is a new coronavirus which started spreading in December 2019 from Wuhan, China. The seroprevalence of SARS-CoV2 antibodies allows to define a better picture of the spread of SARS-CoV2 infection in the population. The duration of SARS-CoV2 antibodies in the healthy population as well as in immunocompromised patients is still a topic of debate. HIV-infected people are at increased risk of developing complications from contracting a viral illness. Furthermore,their ability to develop and maintain an optimal immunological response to any kind of pathogen appears to be reduced.

We analyzed the overall seroprevalence of SARS-CoV2 antibodies in $85 \mathrm{HIV}$ infected-people on ART aged between 5 and 34 years old from May to January 2021. 88,2\% of patients were in a good state of viroimmunological control: 23 showed a $\mathrm{VL}<40 \mathrm{cp} / \mathrm{ml}$ and 52 had an undetectable $\mathrm{VL}$. When positive for SARS-CoV2 serology, a confirmatory nasopharyngeal swab for PCR assessment and a second serological assay would be performed.

Out of the 85 patients, 5 proved to be positive for SARS-CoV2 antibodies (rate of prevalence $5.8 \%$ ). In all 5 cases the nasopharyngeal swabs were negative and the second assay for SARS-CoV2 antibodies performed in 4 out of 5 patients a week later was negative as well. The anamnestic recall brought no elements of suspicion for a past infection.

The duration of SARS-CoV2 antibodies after COVID19 disease is still poorly understood in healthy population and additional studies will be needed to define the durability of humoral responses in immunocompromised children and in particular in HIV infected children under effective ART. It is still unknown whether ART or their immunological impairment may in part mitigate the pathogenesis of SARS-CoV-2 infection. Also, it will be interesting to analyze the impact of vaccination against SARS-CoV2 in HIV infected patients with a satisfactory virological control.

\section{Introduction}

SARS-CoV2 is a new coronavirus which started spreading in December 2019 from Wuhan, China [1]. The impact of the new coronavirus drove growing attention towards the understanding of the immunological process underlying the infection. Specifically, serology for SARS-CoV2 started being tested not only as a way to establish the diagnosis of infection, but also for an epidemiological purpose.

The seroprevalence of SARS-CoV2 antibodies, in fact, allows to define a better picture of the spread of SARS-CoV2 infection in the population, being many people asymptomatic carriers. The first wave of the pandemics in Italy was considered to be between February and June 2020 [2] [3], the second wave started in October 2020 and lasted until December 2021 [4]. Italy went into lockdown from March 9th to May 3rd [5] [6]. The cases of COVID19 in Italy, assessed via PCR for SARS-CoV2, were 230.555 at the end of the second wave [7] out of a population of 60.416 .400 people [8]. The incidence rate of COVID19 cases was $0,3 \%$. The duration of SARS-CoV2 antibodies in the healthy population as well as in immunocompromised patients is still a topic of debate: while some studies support the disappearance of 
antibodies in the healthy population within three months from the infection [9] [10], other support their persistence for several months [11].

HIV-infected people are at increased risk of developing complications from contracting a viral illness. Furthermore, their ability to develop and maintain an optimal immunological response to any kind of pathogen appears to be reduced. [12]

\section{Materials And Methods}

We analyzed the overall seroprevalence of SARS-CoV2 antibodies in 85 HIV infected-people aged between 5 and 34 years old attending their regular follow-up at Bambino Gesù Children's Hospital in Rome from May to January 2021. All patients were regularly assuming their ART. 33 patients showed a detectable HIV VL (mean $77,21 \mathrm{cp} / \mathrm{ml}$ ), with a mean CD4 cell count of 759 cells $/ \mathrm{ml}$. Specifically, out of these 33 patients, 23 showed a VL $<40 \mathrm{cp} / \mathrm{ml}$. The remaining 52 patients had an undetectable HIV VL at enrollement. All patients were tested for SARS-CoV2 IgG by DiaSorin's LIAISON ${ }^{\circledR}$. 38 patients were tested both during the first wave (May to August 2020) and second wave (October 2020 to December 2020) of the pandemics. SARS-CoV2 antibodies were considered to be positive over the range of $12 \mathrm{AU} / \mathrm{ml}$. When positive for SARS-CoV2 serology, patients would undergo a nasopharyngeal swab to detect SARS-CoV2 via PCR as well.

\section{Results}

Out of the 85 tested patients, 4 proved to be positive for SARS-CoV2 antibodies (IgG) and in 1 was detected a borderline value $(12,7 \mathrm{AU} / \mathrm{ml})$ [Table 1]. 3 of the positive results and the 1 borderline result were obtained during the first wave of the pandemics, the fourth positive result instead belonged to the second wave monitoring and was previously seronegative in July 2020.

These 5 patients were all regularly taking their ART, one had a detectable VL $(<40 \mathrm{cp} / \mathrm{ml})$ and their CD 4 mean cell count was $845,6 \mathrm{cell} / \mathrm{ml}$. These 5 patients were then subjected to a nasopharyngeal swab to assess or exclude via PCR the presence of SARS-CoV2 in their upper respiratory tract and underwent a second serological assay as well to confirm at a second evaluation the presence of SARS-CoV2 antibodies. In all 5 cases, the nasopharyngeal swabs were negative and the second assay for SARS-CoV2 antibodies was negative as well. None of the patients reported symptoms such as fever, cough, myalgia or fatigue. None of the patients disclosed to have had recent contacts with suspect or confirmed cases of SARS-CoV2 infection. The anamnestic recall brought no elements of suspicion for a past SARS-CoV2 infection.

We also report that in our cohort two had documented SARS-CoV2 infection (assessed via nasopharyngeal PCR). Unfortunately, no serological assays are available for these two patients yet. These two patients had mild fever and cough, didn't require hospitalization and the negativization for 
SARS-CoV2 PCR occurred within 4 weeks. Their VL at the moment of the infection was negative and their CD4 mean cell/count was $690 \mathrm{cells} / \mathrm{ml}$.

Out of the 5 patients who tested positive for SARS-CoV2 serology, none showed detectable IgG for SARSCoV2 at the following assays. HIV infected people are known to have a lesser ability in building and maintaining an optimal immune response compared to non-HIV infected people. This feature varies according to the stage of infection and how early in their life ART was commenced. [12].

Our data show a slight change in terms of SARS-CoV-2 incidence between the 1st and 2nd wave of the pandemics ( $4,7 \%$ during the 1 st wave versus $1,17 \%$ during the 2 nd wave). 3 patients proved to be positive in the first wave of the pandemics, one proved positive in January 2020. The two SARS-CoV2 infections assessed via nasopharyngeal swab in our cohort occurred in September 2020.

Table 1

Results

\begin{tabular}{ll} 
Number of patients & 85 \\
Age group & $5-34$ y.o. \\
Regularly on ART & All \\
Number of patients tested both during the first and second wave & 38 \\
Number of patients with SARS-Cov2 IgG during the first wave & $3(+1$ \\
$\begin{array}{l}\text { Numbers of patients with SARS-Cov2 IgG during second wave } \\
\text { Number of patients with SARS-CoV2 IgG during first and second wave who proved } \\
\text { positive to following serological assay of SARS-CoV2 PCR assessments }\end{array}$ & value) \\
$\begin{array}{l}\text { Number of patients with SARS-Cov2 IgG who presented symptoms, had known contacts } \\
\text { with SARS-CoV2 infected people or whose anamnestic recall disclosed risk factors for } \\
\text { infection }\end{array}$ & $0(1,17 \%)$ \\
$\begin{array}{l}\text { Number of COVID19 cases in our cohort } \\
\text { Numbo }\end{array}$ & $0(100 \%)$ \\
\hline
\end{tabular}

\section{Discussion}

Seroprevalence in our study demonstrated that more than 5,8\% patients (considering the missing data concerning the two patients who had confirmed COVID19) were at some point in contact with SARS-CoV2 and it' shard to compare this data to the general population's as no major studies of seroprevalence in Italy have been conducted yet. Apparently, none of these patients developed COVID19 and it's uncertain whether this may partially be due to the good viroimmunological control our patients showed or ART. Furthermore, many are the open questions. Were the analysis methods used during the first and second phase of the pandemics reliable? If so, did HIV patients eventually lose their antibody title due to their inability to maintain the serological response and was this data amplified by an insufficient immunological booster given by minimal exposure to the virus? What will the data concerning post- 
vaccination serology be? Will HIV patients develop and maintain an adequate serological response following the vaccination?

\section{Conclusions}

The rate of incidence of seropositive patients in our cohort turned out to be $5,8 \%$ in total, but it's hard to compare these data to the general population's as no major studies of seroprevalence in Italy have been conducted yet. We mean to underline that these patients were all regularly taking their ART, attending their regular follow-up and clinic visits, their VL was undetectable, except for one who had a detectable VL (< $40 \mathrm{cp} / \mathrm{ml}$ ), and their CD4 mean cell count was $845,6 \mathrm{cell} / \mathrm{ml}$. The duration of SARS-CoV2 antibodies after COVID19 disease is still poorly understood in healthy population and additional studies will be needed to define the durability of humoral responses in immune compromised children and in particular in HIV infected children under effective ART. Also, it will be interesting to define how HIV infected people will respond to SARS-CoV2 vaccination. Finally, the two patients who developed COVID19 had no significant complications nor their clinical presentation and management differed from that of another non HIVinfected person, it is still unknown whether ART or their immunological impairment may in part mitigate the pathogenesis of SARS-CoV-2 infection. It's also significant to underline that these two patients showed a good control of HIV infection as well during SARS-CoV-2 infection.

\section{Declarations}

\section{Author Contributions:}

"Conceptualization Chiara Casamento Tumeo and Stefania Bernardi; methodology Carlo Federico Perno and collab.; validation Luana Coltella, Stefania Ranno, Livia Piccioni, Giulia Linardos, Luna Colagrossi, Carlo Concato and Carlo Federico Perno, formal analysis Luana Coltella, Stefania Ranno, Livia Piccioni, Giulia Linardos, Luna Colagrossi, Carlo Concato and Carlo Federico Perno,.; investigation Chiara Casamento Tumeo and Stefania Bernardi; resources Chiara Casamento Tumeo and Stefania Bernardi; data curation Chiara Casamento Tumeo and Stefania Bernardi, writing-original draft preparation Chiara Casamento Tumeo.; writing-review and editing, Chiara Casamento Tumeo, Stefania Bernardi and Nicola Cotugno.; visualization Chiara Casamento Tumeo; supervision Nicola Cotugno and Stefania Bernardi.; project administration, Stefania Bernardi. All authors have read and agreed to the published version of the manuscript."

\section{Funding:}

This research received no external funding.

\section{Institutional Review Board Statement:}

Not applicable 


\section{Informed Consent Statement:}

Informed consent was obtained from all subjects involved in the study.

\section{Ethics approval:}

Approval was obtained from the local ethics committee.

\section{Consent for publication:}

Consent for publication was obtained from the editorial office from our institution.

\section{Availability of data and material:}

Chiara Casamento Tumeo and Stefania Bernardi detain the published data.

\section{Conflicts of Interest:}

The authors declare no conflict of interest

\section{Acknowledgments:}

We mean to acknowledge the key role the Virology laboratory had in analyzing the collected data.

\section{References}

1. P. Zhou, X.-L. Yang, X.-G. Wang, B. Hu, L. Zhang, W. Zhang, H.-R. Si, Y. Zhu, B. Li, C.-L. Huang, H.-D. Chen, J. Chen, Y. Luo, H. Guo, R.-D. Jiang, M.-Q. Liu, Y. Chen, X.-R. Shen, X. Wang, X.-S. Zheng, K. Zhao, Q.-J. Chen, F. Deng, L.-L. Liu, B. Yan, F.-X. Zhan, Y.-Y. Wang, G.-F. Xiao, Z.-L. Shi, A pneumonia outbreak associated with a new coronavirus of probable bat origin. Nature 579, 270-273 (2020). doi:10.1038/s41586-020-2012-7pmid:3201550]

2. Repubblica. ^ Coronavirus, in dieci comuni lombardi: cinquantamila persone costrette a restare in casa. Quarantena all'ospedale milanese di Baggio, accessed on January 2021

3. Gazzetta Ufficiale, www.gazzettaufficiale.it., accessed on January 2021

4. Gazzetta Ufficiale, www.gazzettaufficiale.it, accessed on January 2021

5. Gazzetta Ufficiale,_https://www.gazzettaufficiale.it/eli/id/2020/03/09/20A01558/sg, accessed on January 2021

6. https://www.gazzettaufficiale.it/eli/id/2020/04/11/20A02179/SG, accessed on January 2021

7. Salute.gov.,_www.salute.gov.it/portale/nuovocoronavirus/dettaglioContenutiNuovoCoronavirus.jsp? id=5367\&area=nuovoCoronavirus\&menu=vuoto

8. ISTAT; https://www.istat.it/it/popolazione-e-famiglie, accessed on January 2021 
9. F. J. Ibarrondo, J. A. Fulcher, D. Goodman-Meza, J. Elliott, C. Hofmann, M. A. Hausner, K. G. Ferbas, N. H. Tobin, G. M. Aldrovandi, O. O. Yang, Rapid Decay of Anti-SARS-CoV-2 Antibodies in Persons with Mild Covid-19. N. Engl. J. Med. 383, 1085-1087 (2020).

doi:10.1056/NEJMc2025179pmid:32706954

10. Q.-X. Long, X.-J. Tang, Q.-L. Shi, Q. Li, H.-J. Deng, J. Yuan, J.-L. Hu, W. Xu, Y. Zhang, F.-J. Lv, K. Su, F. Zhang, J. Gong, B. Wu, X.-M. Liu, J.-J. Li, J.-F. Qiu, J. Chen, A.-L. Huang, Clinical and immunological assessment of asymptomatic SARS-CoV-2 infections. Nat. Med. 26, 1200-1204 (2020). doi:10.1038/s41591-020-0965-6pmid:32555424

11. D. F. Gudbjartsson, G. L. Norddahl, P. Melsted, K. Gunnarsdottir, H. Holm, E. Eythorsson, A. O. Arnthorsson, D. Helgason, K. Bjarnadottir, R. F. Ingvarsson, B. Thorsteinsdottir, S. Kristjansdottir, K. Birgisdottir, A. M. Kristinsdottir, M. I. Sigurdsson, G. A. Arnadottir, E. V. Ivarsdottir, M. Andresdottir, F. Jonsson, A. B. Agustsdottir, J. Berglund, B. Eiriksdottir, R. Fridriksdottir, E. E. Gardarsdottir, M. Gottfredsson, O. S. Gretarsdottir, S. Gudmundsdottir, K. R. Gudmundsson, T. R. Gunnarsdottir, A. Gylfason, A. Helgason, B. O. Jensson, A. Jonasdottir, H. Jonsson, T. Kristjansson, K. G. Kristinsson, D. N. Magnusdottir, O. T. Magnusson, L. B. Olafsdottir, S. Rognvaldsson, L. le Roux, G. Sigmundsdottir, A. Sigurdsson, G. Sveinbjornsson, K. E. Sveinsdottir, M. Sveinsdottir, E. A. Thorarensen, B. Thorbjornsson, M. Thordardottir, J. Saemundsdottir, S. H. Kristjansson, K. S. Josefsdottir, G. Masson, G. Georgsson, M. Kristjansson, A. Moller, R. Palsson, T. Gudnason, U. Thorsteinsdottir, I. Jonsdottir, P. Sulem, K. Stefansson, Humoral Immune Response to SARS-CoV-2 in Iceland. N. Engl. J. Med. 383, 1724-1734 (2020).

12. Simone Pensieroso, Alberto Cagigia, Paolo Palma, Anna Nilssona, Claudia Capponi, Elio Freda, Stefania Bernardi, Rigmor Thorstenssone, Francesca Chiodia, and Paolo Rossi, Timing of HAART defines the integrity of memory B cells and the longevity of humoral responses in HIV- 1 verticallyinfected children; Proceedings of the National Academy of Sciences of the United States of America Vol. 106, No. 19 (May 12, 2009), pp. $7939-7944$ (6 pages) 